Cuadernos de Pensamiento $\mathrm{N}^{\circ} 33$

Número monográfico sobre Karol Wojtyla/san Juan Pablo II en el centenario de su nacimiento. Volumen 2. Año: 2020

DOI: https://doi.org/10.51743/cpe.66

tren sueveres

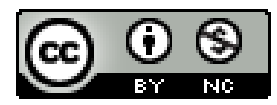

\title{
La escultura como respuesta al amor de Dios a la luz de Juan Pablo II
}

\section{Sculpture as an answer to the Love of God in the light of John Paul II}

\author{
MARIELA GARIBAY \\ Escultora \\ marielagaribay.com
}

\begin{abstract}
RESUMEN: El arte como respuesta al amor de Dios, san Juan Pablo II en su carta dirigida a los artistas realiza una llamada a quienes tienen esta especial vocación hacia la belleza, concibiendo el arte como el bien que salva, como "un puente tendido hacia la experiencia religiosa", como el medio que transformando la materia abre las almas al sentido de lo eterno y las lleva a Dios. El arte se convierte entonces, en una vocación al servicio del bien, capaz, a través de nuestra sensibilidad, de elevar nuestro espíritu, de animar nuestro camino, sobre todo en momentos de confusión y dificultad, de provocarnos asombro, y así devolvernos las ganas de vivir y disfrutar de la belleza que nos envuelve. Es lo que intento plasmar en mi obra como escultura.
\end{abstract}

PALABRAS ClAVE: Juan Pablo II, arte, vocación, escultura, diálogo fe-arte

ABSTRACT: Saint John Paul II in his letter addressed to artists made a call to those who have this special vocation towards beauty, as he conceived art as the good that saves, as "a bridge towards religious experience", as the means that by transforming matter allows souls to open to the sense of the eternal and that leads them to God. 
Art then becomes a vocation at the service of good, capable, through our sensitivity, of elevating our spirit, of enlightening our path, especially in moments of confusion and difficulty, of causing wonder and awe in our souls, and thus giving us back our desire to live and enjoy the beauty that surrounds us. All of this is what I try to capture in my work as a sculptor.

KEYWORDS: John Paul II, art, vocation, sculpture, dialogue between faith and art

$\mathrm{E}$ 1999 San Juan Pablo II dedicó una carta a los artistas, después de la relectura de la carta para este artículo, me doy cuenta que de alguna manera mi forma de trabajar la escultura durante todos estos años mantiene cierta relación con lo que el Santo Padre quiso comunicar a los artistas en esa oportunidad, concibiendo el arte como: "el bien que salva", como "un puente tendido hacia la experiencia religiosa", como un "medio que transformando la materia abre las almas al sentido de lo eterno y las lleva a Dios". Comparto aquí algunas reflexiones alrededor de la carta, publicada en Pascua de Resurrección un 4 de abril en 1999. Empezaré por un comentario sobre la carta y luego explicaré un poco el tema y la inspiración de mi trabajo.

\section{LA VOCACIÓN AL SERVICIO DE LA BELLEZA}

Todos sabemos que San Juan Pablo II tenía una especial sensibilidad para el arte, y tal vez por eso pudo en esta carta dirigirse con tanta verdad y cercanía a los artistas, hablar del don del artista y ver el arte como una vocación especial y necesaria. Su experiencia artística fue a través del teatro, que practicó en su juventud, incluso de forma clandestina por motivo de la invasión a Polonia. Para él la afirmación de Dostoievski "la belleza salvará al mun$d o "$, fue un punto de encuentro con otros artistas que compartían o no su fe. Cito al Santo Padre: "El modo en que el hombre establece la propia relación con el ser, con la verdad y con el bien, es viviendo y trabajando. El artista

\footnotetext{
${ }^{1}$ F. DostoievsKi, El idiota, p. III, cap. V.
} 
vive una relación peculiar con la belleza. En un sentido muy real puede decirse que la belleza es la vocación a la que el Creador le llama con el don del talento artístico". A lo largo de toda la carta nos habla sobre la belleza, pero sobre una belleza en mayúsculas, es hacia esta belleza, a la que el artista tendría que aspirar y responder.

Sobre la Belleza, también nos dice, que es la clave del misterio y llamada a lo trascendente. Es una invitación a gustar la vida y a soñar el futuro, por eso la belleza de las cosas creadas no llena el alma y suscita en los corazones esa nostalgia de Dios, la belleza representa para él, el bien, lo bueno, lo verdadero, a lo que aspira el alma del hombre.

El arte se convierte entonces, en una vocación al servicio del bien, capaz, a través de nuestra sensibilidad, de elevar nuestro espíritu, de animar nuestro camino, sobre todo en momentos de confusión y dificultad, de provocarnos asombro, sentimiento que de niños nos es cotidiano y de adultos a veces parece hemos olvidado, porque hemos permitido que el ritmo de la vida nos quite tiempo para contemplar, en definitiva en este sentido, el arte es capaz de entusiasmarnos, y así devolvernos las ganas de vivir y disfrutar de la belleza que nos envuelve.

\section{UNA ALIANZA FECUNDA ENTRE EVANGELIO Y ARTE}

San Juan pablo II hace también referencia a la estrecha relación a lo largo de dos mil años, entre la iglesia y el arte, se refiere a esta relación, como una alianza en fecundo diálogo entre el evangelio y el arte, alianza que ha regalado al mundo las más bellas obras creadas e imaginadas por los artistas. Nos recuerda las preciosas catedrales románicas, góticas, bizantinas, la música, las pinturas, obras como las de la capilla Sixtina y las esculturas, que en todas las iglesias dan forma y rostro a nuestra fe. Tantas obras de las que realmente se puede decir que han sido y son un puente para con Dios, que nos acercan al Evangelio, a la grandeza de lo eterno, a lo que no se puede explicar con palabras.

También están aquí todas las formas de arte que sirvieron para evangelizar, cuando la imagen era la mejor manera de llevar La Palabra. Obras sa- 
gradas que provocan una profunda admiración ante el observador de hoy, grandes construcciones para el culto, la fuerza y la sencillez del románico, el esplendor del gótico, las expresiones artísticas del medioevo, tremendas y fascinantes. En el renacimiento, con Miguel Ángel, y una gran cantidad, de creadores y creaciones inspiradas por Dios, manifestando en ellas esa misteriosa relación entre el don, el Espíritu y la respuesta. Después de recordarnos esta maravillosa alianza entre los artistas y la iglesia, nos invita a un nuevo diálogo entre el arte y la fe.

\section{HACIA UN DIÁLOGO RENOVADO Y LA LLAMADA A LOS ARTISTAS}

Es clara e impresionante esta historia en común, pero, ¿Qué pasa en la actualidad? ¿Cuál es la relación de la iglesia con el arte actual? Después de todo esto el Papa nos habla de un diálogo renovado, nos explica la necesidad que tiene la iglesia del arte, pero nos pregunta también a los artistas si nosotros tenemos necesidad de la iglesia. Él reconoce que si bien es verdad que: "se han seguido creando obras de cultura y arte, provenientes de un humanismo cristiano, se ha afirmado en los últimos años en nuestra sociedad, una forma de humanismo caracterizado por la ausencia de Dios, y hasta con una profunda oposición a Él. Lo que ha llevado a la separación entre el arte y la fe.”

A pesar de eso, la iglesia ha seguido alimentando un gran aprecio por el valor del arte como tal. Y aquí es donde San Juan Pablo II, dice unas palabras que comparto y agradezco. Él nos dice que "el arte, incluso más allá de sus expresiones más típicamente religiosas, cuando es auténtico, tiene una íntima afinidad con el mudo de la Fe. De modo que hasta en las condiciones de mayor desapego de la cultura respecto a la iglesia, precisamente el arte continúa siendo una especie de puente tendido hacia la experiencia religiosa". Sigue diciendo que "la búsqueda de la belleza, como fruto de la imaginación que va más allá de lo cotidiano, es una especie de llamada al misterio". Y concluye destacando, que "incluso, cuando el arte, escrudiña las profundidades más oscuras del alma o los aspectos más desconcertantes del mal, el artista se hace de algún modo voz de la expectativa universal de la redención." Estas palabras del Santo Padre reflejan una verdad muy actual, 
puesto que el arte para los creadores es ese espacio donde cuestionar y posicionarse, es un intento de explicarse a sí mismos y a los demás, el mundo en que vivimos, de develar sus misterios, es la forma de cómo se interpreta la actualidad y la necesidad de reinventar y explicar en forma de arte todos esos sentimientos e ideas, hasta donde el lenguaje no llega.

El papa también nos recuerda el mensaje de la iglesia a los artistas, de 1965 después del Concilio Vaticano II: "este mundo en que vivimos, tiene necesidad de la belleza para no caer en la desesperanza. La belleza como la verdad, pone alegría en el corazón de los hombres, es el fruto precioso que resiste a la usura del tiempo que une generaciones y las hace comunicarse en la admiración"

En búsqueda de este nuevo diálogo con el arte el afirma entonces que la iglesia ha tenido y tiene necesidad del arte y los artistas, pero luego hace una pregunta. Si hoy el arte, tiene también, necesidad de la iglesia y realiza una llamada directa a los artistas. Es a esta llamada a la que intentaré dar respuesta explicando un poco mi trabajo y por qué para mí la escultura es una respuesta al amor de Dios.

\section{LA ESCULTURA COMO RESPUESTA AL AMOR DE DIOS}

El tipo de arte que realizo no es arte sacro, ni habla directamente de Dios o el Evangelio. Pero seguramente es inevitable que mi vida espiritual, mis creencias y mi experiencia con Dios este delante de los temas que elijo y de mi forma de trabajar. Siempre quise dedicarme a algo que ayude a los demás y descubrí que con el arte también es posible. Ante la necesidad de bien que existe en todos, el arte puede ser ese puente del que nos habla el Papa, para ayudar a los demás. No sé si finalmente mis esculturas cumplen ese objetivo, yo las hago y las entrego con la esperanza que serán, de algún modo, para quien se detiene a verlas, un puente con su interior, con los deseos de felicidad y bien que están en su corazón.

Trabajo con volúmenes, con espacios llenos y vacíos, texturas general-

${ }^{2}$ Mensaje a los Artistas (8 de diciembre 1965): AAS 54 (1966), 13. 
mente muy trabajadas y formas redondeadas, donde lo que busco básicamente es el equilibrio y la armonía. Los personajes que realizo son pretextos, para que, con este juego de volúmenes y equilibrios, consiga crear un lenguaje simple y directo. Busco en mi trabajo que la armonía y el equilibrio nos lleven a la calma, y esta al silencio, este silencio nos invite a mirar dentro de nosotros mismos, y que probablemente esa mirada interior, nos conduzca a la verdad y el bien en nuestro interior.

Mi experiencia es que, según el tipo de trabajo que realizo, que son normalmente modelados en barro para luego ser fundidos en bronce, o modelos en yeso para ser trabajados en mármol, o tallas directas ya sea en madera o piedra. La escultura te exige tener mucha fuerza. Fuerza de voluntad, fuerza en el contenido y fuerza en la forma.

La voluntad, es necesaria porque el trabajo es pesado, es lento y comúnmente te enfrentas a dificultades técnicas que tienes que ir solucionando para ser fiel a la idea y la forma. El contenido, tienen que ser una idea que te siga pareciendo importante de contar, tanto hoy, como mañana, como dentro de dos años, o más, cuando tal vez recién puedas ver tu escultura terminada. $\mathrm{Y}$ la forma, la forma tiene que ser tan potente que, aunque pase por muchas manos en el largo proceso de elaboración, como pasa con la técnica del bronce, la forma resista y se mantenga.

A lo largo de los años, he entendido que la fuerza más grande y real, capaz de mover el mundo y cambiarlo, es el amor. Y es así como se inicia esa búsqueda personal del Amor en mi trabajo, de esa fuerza que Dios puso dentro de cada corazón, la que nos mueve, la que permite cada acto de bien y bondad, la que nos mantiene.

Y es ahí donde busco mis temas, partiendo de la idea de que, las almas siempre apuntan al cielo, que fuimos creados por el Amor, y que tenemos dentro una inclinación natural a volver a Él. Hablo en mis esculturas sobre, la necesidad de una mirada interior, sobre el silencio, la serenidad, la paciencia, la ternura, la confianza, etc., creo que es posible reconocerse a sí mismo cuando algo te evoca a estos sentimientos, porque nos son comunes, porque son parte del bien que tenemos dentro y del bien al que estamos destinados.

Me gusta pensar que alguien al ver una de mis esculturas, se detiene a contemplar y se recuerda, en ella, a sí mismo. Muchas veces recurro a senti- 
mientos de la infancia, la ingenuidad, la sorpresa, el asombro, la confianza absoluta, el deseo de volar o correr, el extender los brazos para sentir el viento o la lluvia, el tumbarte para descansar bajo el sol, cerrar los ojos para escuchar en nuestro interior, todo esto, o lo hemos hecho o lo hemos deseado hacer, es propio de nuestra naturaleza de hijos amados de Dios. Trato también muchos temas sobre a la familia como centro de experiencias del amor, con recuerdos de mi infancia, con mis hermanos y mis padres, tanto como mi experiencia actual como esposa y madre.

En definitiva, mis obras llevan dentro mi confianza en Dios y a mi manera hablo de Él en ellas. Es por eso que me gusta que lleguen a todas partes, porque todos, dentro o fuera de la iglesia, practicantes de otras religiones o de ninguna, tienen esa huella del amor, ese recuerdo inconsciente de confianza plena, y con mis esculturas desearía despertarlo. Es una realidad o debería serlo que quienes tenemos la suerte de haber recibido gratuitamente la fe, de ser personas de oración, de recibir los sacramentos, tengamos más armas para defendernos de la desesperanza, el ruido, la oscuridad en la que nuestro mundo nos sumerge, de la dureza del día a día, como actualmente lo estamos experimentando. Pero en definitiva todos necesitamos rendijas donde descansar la mirada y descubrir imágenes que nos recuerden que fuimos creados en el Amor, que es posible confiar, que alguna vez, sentimos esa confianza plena y una paz inalterable, aunque fuera en nuestra más temprana niñez, y que todo eso que está en nuestro corazón aún está ahí, nos espera, espera a que nos detengamos, reflexionemos, hagamos silencio y volvamos a encontrar ese lugar en nuestro interior donde todo tiene sentido. Por eso tengo por costumbre ofrecer mi trabajo y pedir porque sean un pequeño puente hacia la verdadera felicidad, y así, tal vez, ayudar a que se haga realidad ese puente del que nos habla San Juan Pablo II. Soy consciente que muy posiblemente toda esta explicación sea el intento de dar sentido a mi trabajo y no sé si todos estos propósitos tan personales lleguen mínimamente a cumplirse, pero para mí eso se convierte en una búsqueda que me impulsa a seguir trabajando.

Bajo estas ideas doy gracias por la alegría que me da mi vocación y que la pueda desarrollar, por las puertas abiertas y las posibilidades que tengo de seguir, es por eso que pienso que lo que hago es el intento de dar respuesta al 
inmenso amor de Dios en mi vida. "Por eso el artista, cuanto más consiente es de su "don", tanto más se siente movido a mirar hacia sí mismo y hacia toda la creación con ojos capaces de contemplar y agradecer, elevando a Dios su himno de alabanza. Solo así puede comprenderse a fondo a sí mismo, su propia vocación y misión"3.

${ }^{3}$ Carta del Santo Padre Juan Pablo II a los artistas (4 abril de 1999). 


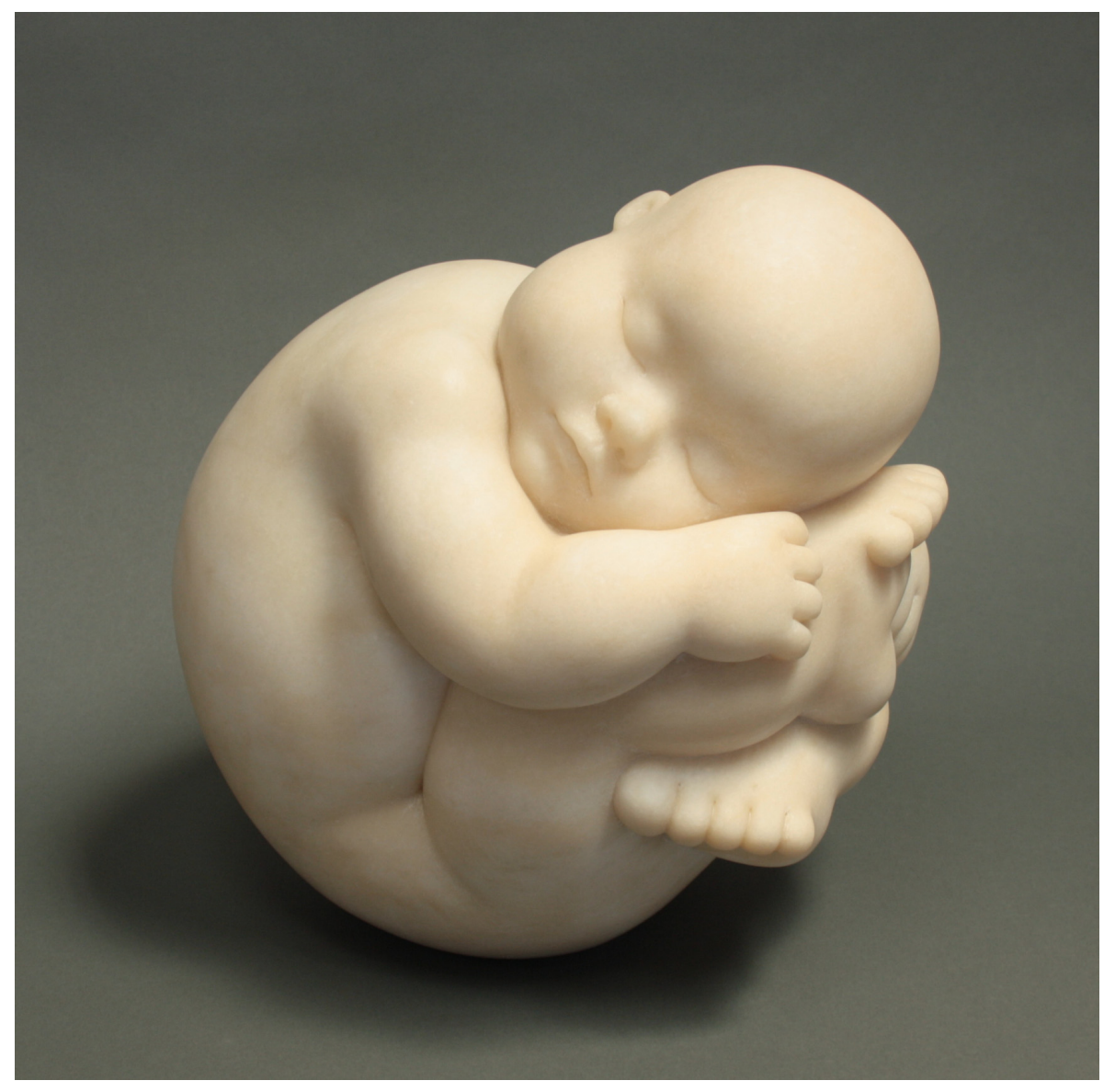

Mariela Garibay, Respuesta, escultura en mármol rosa de Portugal 
